\title{
A pilot acoustic study of Modern Persian vowels in colloquial speech
}

\author{
Robin Aronow, Brian McHugh \& Tessa Molnar*
}

\begin{abstract}
While the current literature on Modern Persian (MP) ${ }^{1}$ shows heightened interest in its vowel inventory, a cogent synchronic account of Modern Persian vowels (MPV) has yet to be presented. Previous phonological descriptions of MPV presuppose a pairing system based on a historical length distinction that is still reflected in MP orthography: /i:, e/, /u:, o/, /p:, æ/. A synchronic phonological analysis of MPV must be based on phonetic measurements; however, existing acoustic studies examine only formal speech, and thus do not reflect colloquial surface forms. Therefore, the goal of this investigation is to lay the groundwork for a comprehensive acoustic study of MPV that presupposes no pairings and is based on colloquial speech in a controlled prosodic environment. Vowel duration and first and second formants were measured using Praat for $90 \mathrm{CVC}(\mathrm{C})$ monosyllables as pronounced phrase-finally in carrier sentences by two Tehrani native speakers: one male, one female. Results show that average durations for each vowel contradicted the traditional length-based pairings. Furthermore, features of the following phonological environment likely to affect vowel length - postvocalic consonant type, coda complexity (CVC vs. CVCC), and adherence to the Sonority Sequencing Principle in complex codas - had no notable effect. Results of formant measurements show the two non-high back vowels to be higher than expected, whereas the high back vowel was noticeably centralized.
\end{abstract}

Keywords. phonetics; acoustic phonetics; Modern Persian; Farsi; Persian vowel system; colloquial speech; vowel space; vowel length; formant frequencies

1. Introduction. The intent of this study is to provide an optimal synchronic account of the vowel system of Modern Persian (MP). Early descriptions of MP vowels (MPV) were rooted in an abstract taxonomy modeled on the vowel system of Classical Arabic, which consists of three long vowels /i:, u:, a:/, and their short counterparts /i, u, a/. This translates into a MPV paired system in which the three "long" vowels /i:, u:, p:/ have corresponding "short" counterparts in the vowels /e, o, æ/. And while those two groups are in fact reflexes of Middle Persian long and short vowels, in MP this length distinction is a historical artifact.

1.1. DiACHRONIC BACKGROUND. MP belongs to the Iranian branch of Indo-Iranian within the Indo-European language family. The evolution of its present vowel system can be traced through the following three widely agreed-upon periods: Old, Middle, and New or Modern Persian. The vowel inventory of Old Persian, shown in (1), consisted of six vowels classified into three pairs based on length, as well as two diphthongs: /aj/ and /aw/ (Windfuhr 2009).

\footnotetext{
* We wish to thank Lydia Spanier and Steven Panek for their assistance with the research on which this paper is based. Authors: Robin Aronow, Temple University (raronow@temple.edu), Brian McHugh, Temple University (bmchugh@temple.edu) \& Tessa Molnar, Temple University (tessa.victoria.molnar@temple.edu).

${ }^{1}$ In this paper we are using the term Modern Persian to refer only to Farsi, the variety of New Persian currently spoken in Iran; thus neither Dari nor Tajik fall within the scope of our investigation.
} 
(1) Old Persian vowel system (after Windfuhr 2009)

i: $\mathrm{i} \quad \mathrm{u} \mathrm{u}$ :

aj aw

a a:

These pairs remained generally stable throughout the Middle Persian period, while the diphthongs /aj/ and /aw/ simplified to become the mid, long vowels /e:/ and /o:/ respectively, yielding an eight-vowel inventory, shown in (2).

(2) Middle Persian vowel system (after Windfuhr 2009)

$\begin{array}{lr}\text { i: } \text { i } & \text { u u: } \\ \text { e: }<\text { aj } & \text { aw }>\text { o: }\end{array}$

a a:

The Early New Persian period began with the influence of the seventh-century Arab conquest (Windfuhr 2009), which led to the adoption of the Arabic alphabet. Over the course of Early New Persian's development into Modern Persian, the vowel system underwent the restructuring shown in (3) (Miller 2012), whereby the long mid vowels raised to merge with their long high counterparts while the short high vowels lowered to become mid, and the long and short low vowels diverged in quality, with /a/ fronting to $/ \mathfrak{x} /{ }^{2}$ and $/ \mathrm{a}: /$ backing and rounding to $/ \mathrm{p}: /$.

(3) Early New Persian vowel system and its shifts to Modern Persian (after Miller 2012)

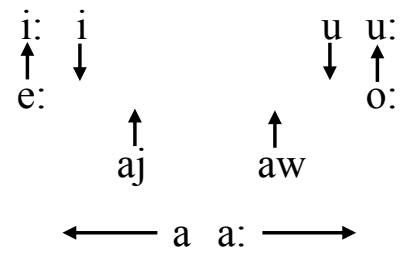

Descriptions of the vowel system at this time were rooted in an abstract taxonomy modeled on the vowel system of Arabic, which consists of the three long vowels /i:, u:, a:/ and their short counterparts $/ \mathrm{i}, \mathrm{u}, \mathrm{a} /$. This resulted in a paired system for MPV in which the three "long" vowels /i:, u:, $\mathrm{p}: /$ have corresponding "short" counterparts /e, o, æ/, shown in (4) with the addition of the diphthongs /ej/ and /ow/ (Miller 2012).

(4) Modern Persian vowel system (after Miller 2012)

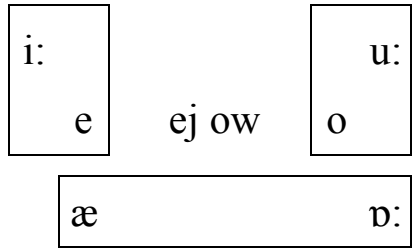

And while those two groups are in fact reflexes of Middle Persian long and short vowels, in MP this length distinction is now merely a historical artifact.

\footnotetext{
${ }^{2}$ In word final position, short /a/ not only fronted but also raised to merge with /e/.
} 


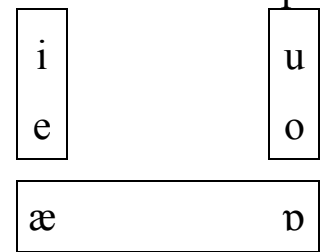

1.2. SynCHRONIC STUDIES. More recent studies show quantity-based descriptions yielding to quality-based descriptions, while maintaining the pairing system based on historical length, as shown in (5) above. Lazard (1992) refers to the historically long vowels (HLV) and historically short vowels (HSV) as stable and unstable, respectively; Serish \& Kambuziya (2005) posit that the distribution of HLV vs. HSV is constrained by specific syllabic structures; Rahbar (2009) correlates HLV and HSV with [ \pm tense]; while Toosarvandani (2004) and Rahbar (2012) argue that length distinctions are reflected in vowel harmony patterns. Curiously, these studies, which treat length as a salient underlying feature, either do not consider or are not informed by valid acoustic measurements. Studies that did incorporate acoustic measurements used formal readings of literary prose (Samareh 1977), self-recordings of formal speech (Toosarvandani 2004), or measurements from a database of recordings (FarsDat) uncontrolled for dialect, age, or socioeconomic status (Gharavian 2000). In two purely acoustic studies that measured only formant values and not duration, Esfandiari et al (2015) rely on news broadcast recordings, while Ansarin (2004) recorded only six words as pronounced by female speakers.

We argue that length distinction is now an abstraction, and that the notion of pairings based on quality and/or quantity must cede to a description in which pairings are no longer presupposed and quality features are the determinants of vowel space. We thus provide a detailed examination of acoustic properties of MPV, in which empirical evidence is presented in support of abandoning the notion of length pairings.

2. Experiment. Since it is generally agreed that the MPV system is undergoing a transition (Rahbar 2009, Miller 2012), the disparities between abstract phonemic forms and phonetic surface forms must be probed. Specifically, in order to achieve a cogent, synchronic account of MVP, this study looks at natural, colloquial speech, examining the duration and first and second formant measurements of surface forms.

2.1. PARTICIPANTS. One male and one female speaker of the Tehrani dialect of MP were selected as participants. Both lived in Tehran, Iran until their mid-twenties. At the time of the study, neither had been residing in the U.S. for more than three years.

2.2. STIMULI. The stimuli consisted of $90 \mathrm{CVC}(\mathrm{C})$ monosyllables of three relevant types:

1. CVC words with singleton codas, e.g., /sib/ 'apple'

2. CVCC words with complex codas that adhere to the Sonority Sequencing Principle ([+SSP]), e.g., /pelk/ 'eyelid'

3. CVCC words with complex codas that violate the Sonority Sequencing Principle ([-SSP]), e.g., /næbz/ 'pulse'

In light of the cross-linguistic tendency for vowels to lengthen before voiced consonants, postvocalic consonants were classified as sonorants [+son], voiced obstruents [-son, + vce] or voiceless obstruents $[-$ son, - vce] for the purpose of examining the effects of consonant type, yielding nine 
different token types (Figure 1). Monosyllables were chosen to ensure that no vowel was unstressed. Each word was embedded in a carrier sentence in phrase-final position in order to control for prosodic environment.

\begin{tabular}{|c|c|c|c|}
\hline & $\mathrm{CVC}$ & $\mathrm{CVCC}[+\mathrm{SSP}]$ & $\mathrm{CVCC}[-\mathrm{SSP}]$ \\
\hline$[-$-son,,- vce $]$ & /yek/ 'one' & /mpst/ 'yogurt' & /fekr/ 'mind' \\
\hline$[-$-son, + vce $]$ & /miz/ 'table' & /dozd/'steal, thief' & /Gpbl/ 'before' \\
\hline$\ldots[+$ son $]$ & /xun/ 'read' & /molk/ 'land, house' & /hæml/ 'carry, burden, load' \\
\hline
\end{tabular}

Figure 1. Sample tokens classified according to coda type by postvocalic consonant type

2.3. Methodology. Participants were administered a pretest in which non-test item monosyllables were presented, initially alone on a computer screen, then embedded in a carrier phrase. (All stimuli were written in Persian script.) Participants were asked to read the single word aloud, then to read the sentence twice aloud. They were coached to use colloquial speech style. The test itself was administered in one sitting, using the same procedure as the pretest, with all test items randomized, and using the same carrier sentence for each trial:

$$
\text { در حال حاضر من مىگیى كه و از }
$$

'Right now, I am saying the word

Measurements were taken solely for the second occurrence of each word to compensate for any stylistic effect the reading of the carrier sentence might have had (cf. Bell 1997). The target words were then extracted from the sentence and analyzed in spectrogram form using Praat 5.4.08 software for vowel length and first and second formant frequencies. Length was measured from the onset of vocality to the onset of the following consonant. Average frequency for the first and second formants was measured across the duration of each vowel.

\section{Results and Discussion.}

3.1. DuRATION. Mean durations for each vowel, as shown in Figure 2, contradict traditional length-based pairings. Moreover, HSVs /e, o, æ/ are all longer than their traditionally "long" counterparts /i, u, p/. For example, HLV /u/ shows a duration of $116.12 \mathrm{~ms}$, whereas its HS counterpart, /o/ had a duration of $135.70 \mathrm{~ms}$. Interestingly, our results also showed the two high HLVs /i, u/ were markedly shorter than the four non-high vowels.

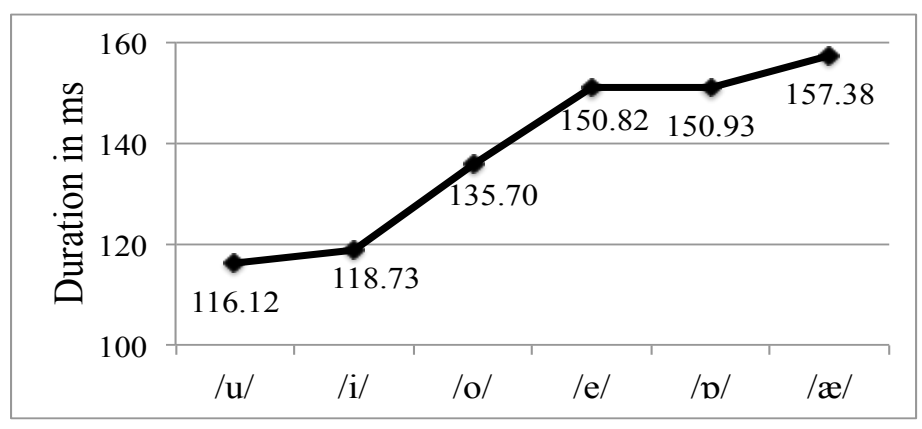

Figure 2. Average vowel durations in milliseconds 
Syllable structure had little bearing on vowel length; mean overall duration in relation to coda complexity spanned a range of less than 2 milliseconds across the three relevant syllable types: CVC, CVCC [+SSP], CVCC [-SSP], as shown in Table 1.

\begin{tabular}{|l|c|c|c|c|c|c|c|}
\hline & $/ \mathrm{i} /$ & $/ \mathrm{e} /$ & $/ \mathrm{u} /$ & $/ \mathrm{o} /$ & $/ \mathrm{v} /$ & $/ \mathfrak{m} /$ & All Vs \\
\hline CVC & 122.23 & 156.72 & 122.08 & 123.02 & 180.59 & 148.48 & 138.68 \\
\hline CVCC [+SSP] & 127.68 & 138.46 & 99.56 & 189.34 & 159.83 & 157.89 & 137.55 \\
\hline CVCC [-SSP] & 104.52 & 149.05 & 114.79 & 142.91 & 115.76 & 166.99 & 139.52 \\
\hline
\end{tabular}

Table 1: Average durations in milliseconds by syllable type

There was no consistent correlation of vowel length with postvocalic consonant type (sonorant, voiced obstruent, voiceless obstruent), as can be seen in Figure 3. Across all vowels, average duration was greatest (148.76 $\mathrm{ms}$ ) when the vowel preceded a voiced obstruent, while it was $137.56 \mathrm{~ms}$ before sonorants and $132.95 \mathrm{~ms}$ before voiceless obstruents. This pattern was not replicated in all of the vowels taken individually.

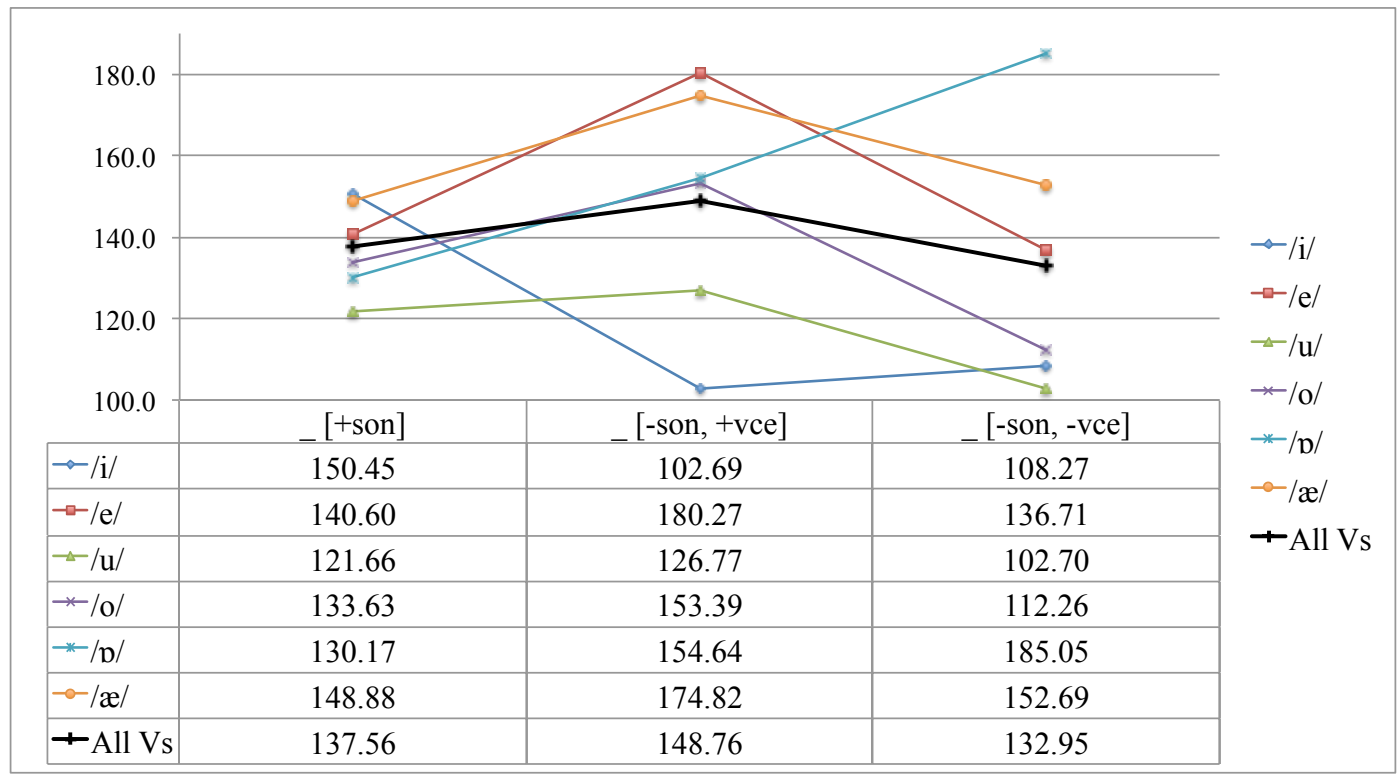

Figure 3. Vowel Duration Averages Based on Postvocalic Consonant Type

Individual vowels exhibited patterns of unclear significance. /u, o, e, æ/ showed the longest durations when preceding voiced obstruents, whereas / $\mathrm{p} /$ was longest before voiceless obstruents, and /i/ was longest before sonorants. The two low vowels / $\mathrm{p} /$ and /æ/ showed shortest durations when preceding sonorants, while /e, o, u/ were shortest before voiceless obstruents and /i/ was shortest before voiced obstruents.

3.2. FormANT FREQUENCIES. Due to physiological differences in vocal tract size, separate vowel spaces were plotted for the male and the female participant on the basis of first and second formant frequency (Figure 4). Scatter plots were based simply on F2 x F1 rather than F2-F1 x F1, as the goal was not to normalize vowel space or eliminate outliers. 
Female: F2 (Hz)

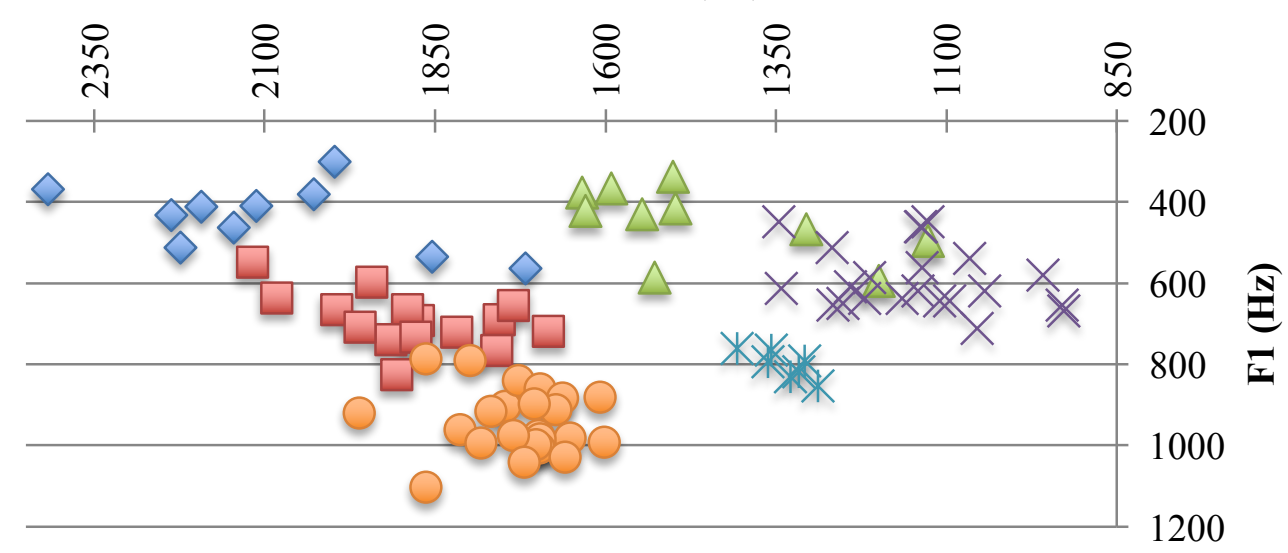

$\diamond / \mathrm{i} / \square / \mathrm{e} / \Delta / \mathrm{u} / \times / \mathrm{o} / \quad * / \mathrm{p} / \odot / \mathfrak{a} /$

Figure 4. Formant measurements for female (above) and male speaker (below)

Male: F2 (Hz)

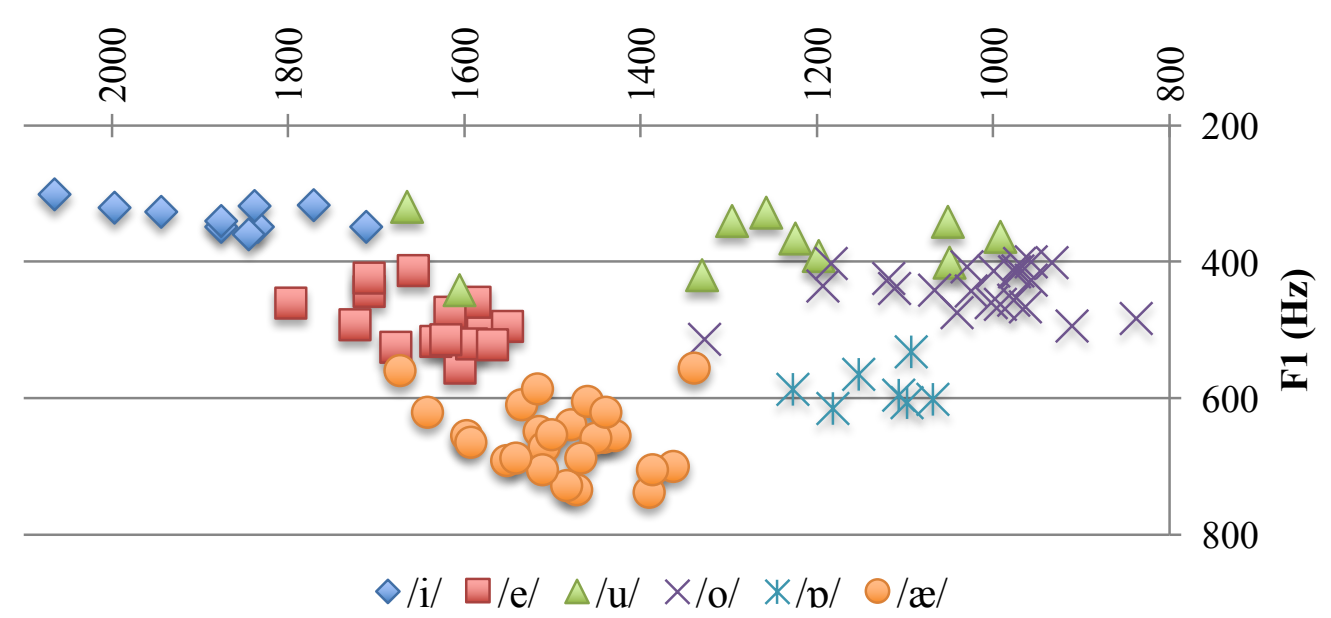

The plotted vowel spaces show front vowels widely spaced along the full spectrum of height, whereas the back vowels show a different type of distribution. In particular, $/ \mathrm{p} /$ is raised to the verge of becoming [o], /o/ is also quite raised and backed, and many tokens of $/ \mathrm{u} /$ are noticeably centralized.

4. Conclusion. Until present, previous phonological descriptions of MPV have presupposed a pairing system based on an historical length distinction consisting of three long vowels and their three corresponding short vowels. Although more recent studies have suggested that vowel length (quantity) is no longer a distinguishing feature of MPVs, these have been based on measurements taken from samples of formal speech, and thus do not reflect colloquial surface forms. Moreover, theoretical descriptions are currently still presented within the framework of pairings based on abstract length. The goal of this pilot study has been to examine the acoustic features of MPVs based on colloquial speech in order to provide a synchronic description of this vowel space. 
Initial findings revealed an inverse correlation between length and non-low historically long vowels, such that /i, u/ show shorter durations than /e, o/. Furthermore, neither syllable type nor postvocalic consonants had any notable influence on vowel durations. In fact, unlike languages such as English in which voiced postvocalic consonants cause vowel lengthening, our results showed $/ \mathfrak{p} /$ and $/ \mathfrak{a} /$ to be shortest before sonorants, and / $\mathfrak{p} /$ to be longest before voiceless obstruents. First and second formant frequencies showed front vowels plotted across vowel space as would be predicted. However, non-high back vowels /o, p/ seem to have undergone raising ${ }^{3}$, whereas the high back vowel /u/ has become centralized.

Our ultimate aim has been to provide a solid empirical foundation for a synchronic account of the MPV system's phonological behavior, and a better understanding of its future trends. With this goal in mind, a broader acoustic study needs to be carried out with a larger number of participants and a wider variety of stimuli, namely words of more than one syllable, as well as syllables that are both open and closed. Overall, these preliminary findings strongly suggest that abstract MPV pairings based on historical length are obsolete, and that new parameters are needed to provide a synchronic account of the MPV system.

\section{References}

Ansarin, Ali. 2004. An acoustic analysis of Modern Persian vowels. Conference on Speech and Computer (SPECOM) 9. 315-318.

Bell, Allan. 1997. Language Style as Audience Design. In Sociolinguistics: A reader (pp. 240250). doi:10.1007/978-1-349-25582-5_20.

Esfandiari, Nasim et al . 2015. Vowel classification and vowel space in Persian. Theory and Practice in Language Studies. 5(2). 426-434.

Gharavian, Davood et al . 2000. An experimental multi-speaker study on Farsi phoneme duration rules using automatic alignment. Speech, Science \& Technology (SST) 8. 186-191.

Lazard, Gilbert. 1992. A grammar of contemporary Persian. Costa Mesa, CA: Mazda Publishers. Miller, Corey. 2012. Variation in Persian vowel systems. Orientalia Suecana, 61, 156.

Rahbar, Elham. 2009. On contrasts in the Persian vowel system. Toronto Working Papers in Linguistics, http://twpl.library.utoronto.ca. 31.

Rahbar, Elham. 2012. Aspects of Persian phonology and morpho-phonology. Toronto: University of Toronto dissertation.

Samareh, Yadollah. 1977. The arrangement of segmental phonemes in Farsi. Tehran: University of Tehran, Faculty of Letters.

Serish, Mehdi \& Aliyeh K. Z. Kambuziya. 2005. Sonority in cvec syllables in Persian. Journal of Language and Linguistics. 4(1). 121-134.

Toosarvandani, Maziar. 2004. Vowel length in Modern Farsi. Journal of the Royal Asiatic Society. 14(3). 241-251.

Windfuhr, Gernot. 1997. Persian phonology. In Kaye, Alan (ed.), Phonologies of Asia and Africa: including the Caucasus. vol. 2, 675-689. Winona Lake, IN: Eisenbrauns.

Windfuhr, Gernot. (Ed.). 2009. The Iranian languages. New York, NY: Routledge.

\footnotetext{
${ }^{3}$ The raising of $/ \mathrm{o}, \mathrm{v} /$ could be suggestive of an incipient back vowel shift.
} 